\title{
Environmental issues of agriculture as a consequence of the intensification of the development of agricultural industry
}

\author{
Eleonora Tsoraeva ${ }^{1, *}$, Alan Bekmurzov ${ }^{2}$, Soslan $\mathrm{Kozyrev}^{3}$, Alan $\mathrm{Khoziev}^{3}$, and Aslanbek \\ Kozyrev $^{3}$ \\ ${ }^{1}$ I.T. Trubilin Kuban State Agrarian University, 350044, Krasnodar, 13 Kalnina str., Russia \\ ${ }^{2}$ North Ossetian state University, 360025, Vatutina str. 46, Vladikavkaz, Russia \\ ${ }^{3}$ Gorsky State Agrarian University, 362040, Kirova str.37, Vladikavkaz, Russia
}

\begin{abstract}
The paper deals with the environmental issues of agriculture. Examples are given that pose a threat to the vital activity of living organisms from various types of agricultural and human activities. The subject of the study is the analysis of environmental issues arising from the intensification of the development of agricultural industry. Intensive agricultural activity leads to pollution of surface rivers, lakes, seas and groundwater, soil degradation and aquatic ecosystems; violation of the water regime in large areas during drainage and irrigation; desertification due to wind erosion; destruction of natural habitats of living organisms of flora and fauna. An urgent problem of agriculture is a decrease in the content of vitamins and microelements in crop production and the accumulation of harmful substances in them. The reasons for these negative processes are soil degradation, intensification of agricultural production.
\end{abstract}

\section{Introduction}

Modern people living in a high-tech and urbanized world are very concerned about ecology and healthy eating. This circumstance gives rise to a steadily growing demand for the socalled "environmentally friendly food" [1]. Since people often understand very different things by this term, it is very difficult to give it an exact definition. The only thing that can be said without offending the truth is that organic food is one that has been grown with minimal or no fertilizers, chemicals and GMOs.

According to the definition of the Congress, adaptive agriculture is "an integrated system of technologies for the production of plant and livestock products, which has specific features, which will allow maintaining the ecological balance of nature in the future and restoring natural resources on which the agricultural economy depends.

\footnotetext{
* Corresponding author: elionora@list.ru
} 


\section{Results}

The agricultural sector adversely affects the external environment. Environmental issues in agriculture are caused by the poor condition of water, air and soil.

Global environmental issues in agriculture.

Livestock and crop production are sectors designed to provide people with food. Agriculture is significant for the economy of every country, it provides over 100 jobs for the population of any city. As a result of production, numerous problems arise that harm the environment. These include: soil erosion; pollution of the seas; rivers and lakes, groundwater; chemical pollution of the top layer of the earth; extinction of some species of animals and plants (due to the destruction of habitats). Each of them contributes to the deterioration of the environment. Soil erosion - this process destroys the top layer of the earth. Its particles are carried away by wind and water flows. The natural conditions of the process do not pose a threat. Erosion reduces fertility and yields.

Surface water pollution. Almost $70 \%$ of all fresh liquid is spent on the needs of agriculture. The main source of pollution is livestock farms. Manure that gets into the water is a serious environmental problem.

Fish and forestry waste are dumped into fresh water bodies. As a result, the acidity of the soil increases. Heavy rains form runoffs that destroy wildlife [2].

Chemical pollution of the earth. The use of chemicals and pesticides helps control weeds, insects and pests. Toxic components accumulate in the ground and penetrate into plants, the fruits and roots of which are consumed. As a result, food becomes lifethreatening for humans and animals. This environmental issue cannot be ignored.

In Russia, the pursuit of the harvest turned into a disaster for the Krasnodar Territory. $\mathrm{He}$ is the leader in the number of cancers. It is forbidden to swim in the local reservoir. Poisonous chemicals are found not only in the soil, but also in the air. Part of the fertilizer is washed off into the Sea of Azov and nearby rivers [3-5].

Destruction of flora and fauna. As a result of deforestation, the expansion of pastures, the construction of settlements, the construction of communication networks, habitats of plants and animals are being destroyed. The development and protection of agriculture leads to the disappearance of $3 \%$ of flora and fauna.

The impact of agriculture on the outside world is greater than any industry. The basis is the need for large territories. Continents are changing. Agricultural lands are not ready for such consumer appeal. Agriculture has the most adverse effect on the state of the soil. The following elements of its influence are distinguished: soil drainage; reclamation; clearing farmland from natural vegetation; use of pesticides and mineral fertilizers. The results of a careless attitude to nature provoke a number of environmental troubles: loss of humus, soil erosion, destruction of soil ecosystems, land compaction $[6,7]$.

Environmental issues from the impact of animal husbandry on the external environment are as follows: penetration of untreated waste into the soil; grazing too many animals, after which the system is unable to repair the damage. A decrease in the level of trace elements and production intensity appears due to the destruction of the soil.

Causes of Environmental Problems in Rural Areas

The main source of environmental pollution in rural areas is livestock production. In the course of development, the condition of the topsoil and surface waters deteriorates. Cause of contamination:

- Lack or excessive amount of organic fertilizers.

- Soil nutrition deteriorates and fertility decreases.

- Inappropriate handling of manure, which can make the fields near farms unusable for a long time. 
- Deterioration of rural infrastructure. Today their ecological condition is a serious problem.

- Excessive irrigation has a negative effect on the state of soils in rural areas. In hot climates, the process leads to salinization. The soil becomes unsuitable for cultivation [8].

It is also necessary to consider the impact of human activities on the natural environment, including agriculture. Environmental monitoring of agricultural land in the Krasnodar Territory is carried out by the Agrochemical Service of the Krasnodar Territory. According to the data of 2019, the service carried out work on the ecological and toxicological assessment of agricultural soils. Heavy metals, pesticide residues, nitrates, and radioactive substances were determined.

The ecological and toxicological assessment of lands and agricultural products was carried out by means of local monitoring studies at permanently fixed stationary areas of the region, as well as by performing a comprehensive agrochemical survey of soils (selectively in mixed samples).

During radiological monitoring, the following were determined from the most toxic and long-lived radionuclides: strontium-90 and cesium-137. In addition, radium-226, thorium232, potassium-40 were measured at reference sites.

Table 1. Initial data for environmental monitoring as of 01.01.2020.

\begin{tabular}{|c|c|c|c|c|c|c|c|c|c|c|c|c|c|}
\hline \multirow[b]{2}{*}{$\dot{z}$} & \multirow{2}{*}{ 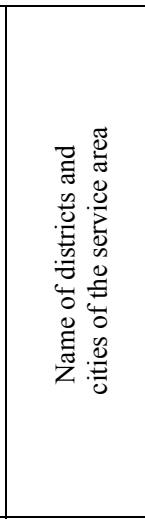 } & \multirow{2}{*}{\multicolumn{2}{|c|}{ 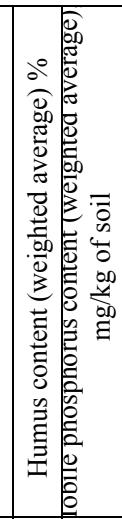 }} & \multirow{2}{*}{ 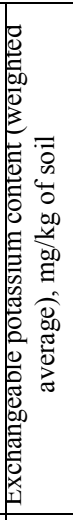 } & \multirow{2}{*}{ 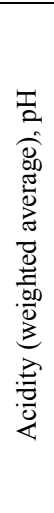 } & \multicolumn{6}{|c|}{ Content of pollutants (heavy metals) in soil, $\mathrm{mg} / \mathrm{kg}$} & \multicolumn{2}{|c|}{$\begin{array}{c}\text { Content of } \\
\text { pollutants } \\
\text { (pesticides) in soil, } \\
\mathrm{mg} / \mathrm{kg}\end{array}$} \\
\hline & & & & & & 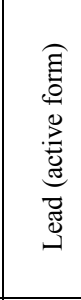 & 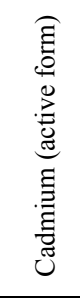 & 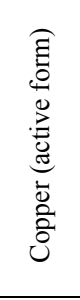 & 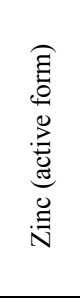 & 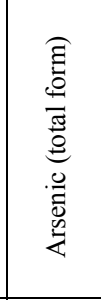 & 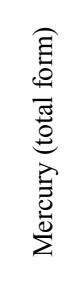 & $\begin{array}{l}\underset{T}{\Xi} \\
\underset{W}{J}\end{array}$ & 穴 \\
\hline 1 & Armavir & 4.1 & 28 & 364 & 6.4 & - & - & - & - & - & - & - & - \\
\hline 2 & $\begin{array}{l}\text { Primorsko- } \\
\text { Akhtarsky }\end{array}$ & 3.5 & 30 & 560 & 6.9 & 0.65 & 0.043 & 0.200 & 0.460 & 7.5-9.4 & 0.024 & 0.001 & 0.065 \\
\hline 3 & Seversky & 3.1 & 46 & 363 & 5.3 & 0.99 & 0.038 & 0.245 & 0.700 & $5.0-8.2$ & 0.062 & 0.001 & 0.041 \\
\hline 4 & $\begin{array}{l}\text { Goryachy } \\
\text { Klyuch }\end{array}$ & 2.7 & 28 & 269 & 4.8 & - & - & - & - & - & - & - & - \\
\hline 5 & Krasnodar & 3.5 & 29 & 324 & 5.3 & 1.43 & 0.204 & 0.2 & 0.84 & $6.9-11.6$ & 0.022 & 0.001 & 0.028 \\
\hline 6 & Sochi & 4.4 & 65 & 129 & 5.2 & 1.39 & 0.310 & - & - & 0.6 & 0.017 & 0.001 & 0.001 \\
\hline 7 & Gelendzhik & 2.8 & 68 & 172 & 6.5 & 1.39 & 0.310 & - & - & 0.6 & 0.017 & 0.001 & 0.001 \\
\hline
\end{tabular}

Radiochemical analysis of soil and agricultural products for strontium-90 was carried out by oxalate precipitation in combination with beta-radiometric and beta-spectrometric measurements, cesium-137 by gamma-spectrometry.

Radiometric measurements were carried out on a gamma - beta spectrometer using the Progress software, the gamma background of the area was determined using the DRG-01T1 device. 
During the analytical control of pesticide residues in soil and agricultural products, special attention was paid to highly persistent and highly toxic substances. Organochlorine compounds and copper-containing preparations were determined.

Residual amounts of pesticides were determined by gas-liquid chromatography using chromatographs "Tsvet-500M" and "Tsvet 800".

The assessment of heavy metal contamination included the number of total and active compounds. From toxic elements, substances belonging to the first and second hazard classes were determined: mercury, lead, arsenic, zinc, copper, cadmium.

The determination of arsenic was carried out by the colorimetric method, mercury using the device "Julia - $5 \mathrm{~K}$ ", the rest of the heavy metals were determined by the atomic absorption method using the device "Kvant-2A".

When assessing pollution levels, the standards in force in the Ministry of Health of Russia and the system of agrochemical service were taken as a basis.

Lead. The factors affecting the accumulation of lead in the soil are almost the same as those of cadmium, zinc, copper, etc. According to research data, the content of lead in the soils of the surveyed areas is in the range of $0.39-1.08 \mathrm{mg} / \mathrm{kg}$, which corresponds to a low content. No excess of the maximum permissible concentration for lead in the farms was found.

Cadmium. The content of active forms of cadmium, an element of the 1st hazard class, is in the range of $0.046-0.070 \mathrm{mg} / \mathrm{kg}$.

Some of the reasons for its accumulation in the soil are natural soil-forming factors, long-term use of mineral fertilizers, etc. Its biological half-life is one of the longest (1100 years) [9]. Even in very small amounts, cadmium has a high toxic effect. Due to the high mobility in the soil, its accumulation in agricultural products can occur even when its content in the soil is less than the hygienic standard. The detected amount of cadmium in the analyzed samples did not exceed the permissible level.

Copper. One of the main trace elements. In large quantities, it is a toxic element of the 2nd hazard class. The content of its total forms in the soils of farms varies within the range of $0.11-1.5 \mathrm{mg} / \mathrm{kg}$.

Zinc. One of the main microelements, which determines and regulates many life processes. At the same time, in high concentrations, zinc is a toxic element. According to its toxicity, it belongs to hazard class 1 .

According to research results, the content of zinc in soils is within $0.26-2.40 \mathrm{mg} / \mathrm{kg}$. Such a distribution of zinc in soils fits into the framework of the generally accepted theory of the transformation of heavy metals in agroecosystems, depending on the natural characteristics of soils and their total input with atmospheric precipitation and means of chemicalization. The amount of zinc above the maximum permissible level was not found in agricultural lands.

Arsenic. Of all the pollutants under study, arsenic, an element of hazard class 1, occupies a special place. Our research has established a relatively high content of arsenic in the soils of agricultural lands of the surveyed farms.

Under the conditions of the Krasnodar Territory, a very high level of arsenic pollution according to existing standards is apparently caused not so much by technogenic (emissions from enterprises, the introduction of agrochemicals, etc.), but by natural factors (genesis of the region's soils, the nature of parent rocks, mineralogical composition, etc.). Proceeding from this, the existing principle of development of the maximum permissible norms for soils by the State Sanitary and Epidemiological Supervision, apparently, needs to be improved. A more detailed differentiation of the dependence of arsenic content on soil properties is required [10].

It should be noted that the revealed relatively high content of arsenic in the soil does not have a negative effect on adjacent environments. The amount of arsenic in cultivated 
agricultural products does not exceed the maximum permissible concentration (data from certification studies).

Mercury. Element of hazard class1, highly toxic. Mercury is a rare element in the environment. According to research data of the agrochemical center, the content of this metal in soils ranges from 0.017 to $0.021 \mathrm{mg} / \mathrm{kg}$. Soils with mercury content above the maximum permissible concentration have not been identified. The detected amount of mercury is related to background pollution and does not pose a danger to human health.

Selective control of soil samples showed that in most cases, residues of organochlorine pesticides were found in the surveyed fields. Basically, their content was below the maximum permissible concentration (MPC). The exception is, as a rule, agricultural lands under perennial plantations and fields adjacent to chemical warehouses, fertigation and irrigation unit, and runways.

According to the criteria for environmental assessment of the state of land, an area with an excess of sanitary standards at the level of 1 MPC is considered relatively satisfactory, with an excess of standards above 2 MPC - emergency.

\section{Discussion}

Ways to solve environmental issues. Scientists identify 4 ways for combating soil disturbance:

1. Precision farming is an organization of agricultural management. It is based on the idea of unevenness in the fields. It provides for the use of GPS systems, variable rate production, crop estimation, remote sensing of the land, geographic information systems. The program reduces the negative impact on the external environment. The efficiency and productivity of the agricultural sector is improving.

2. Organic agriculture helps to reduce the negative consequences of environmental management. It is based on the concept of health, justice, ecology and care. The goal is to improve the condition of animals, people, soil.

3. Conservation agriculture protects against destruction. The key point in the operation of the system is grain-fallow crop rotations. The system is used in arid regions: the steppe part of Siberia and in northern Kazakhstan. It provides a high yield of products.

4. The way of chemicalization of agriculture provides for the harmless use of chemicals for the following tasks: improving the condition of the crop; increasing animal production; beneficial effect on soil condition; protection of crops from bacteria and insects.

Improvement of the ecological situation in the agricultural industry can be achieved only by agreeing on the goals of agricultural production in the context of requirements and restrictions: rational use of natural resources should be the main component of agriculture $[11,12]$.

\section{Conclusions}

The conclusion of experts in the field of protecting the external environment from agricultural pollution suggests that states are developing ways to deal with environmental issues. Alternative energy sources, development of methods for disposal of household waste, anti-radiation measures are used. There are a number of programs for the protection of small rivers: afforestation of the headwaters, construction of dams without flooding the floodplain lands, monitoring the work, and stopping the plowing of floodplain lands. Methods and technologies of farming are being developed that eliminate or prevent the emergence of negative factors of influence on the ecological state of the environment. Environmental issues in agriculture should be taken under the special control of the state. 
Knowledge of their causes and ways of eliminating negative consequences will improve human living conditions in individual territories.

\section{References}

1. S.A. Bekuzarova, S.S. Basiev, A.Kh. Kozyrev, T.A. Dulaev, V.I. Buyankin, Ecological significance of winter camelina in biological agricultures, Journal of Pharmaceutical Sciences and Research 10, 4, 893-895 (2018)

2. L.M. Dokuchaeva, et al. Techniques that exclude negative processes in the soils of irrigated agricultural landscapes of the chernozem zone of the south of Russia, Scientific journal of the Russian Research Institute of Melioration Problems 1 (1), 4 (2011)

3. M.Y. Kalinichenko, N.I. Stojanov, D.V. Abornev, S.V. Ovchinnikova, Optimization of the regeneration of the sodium-cation ion-exchange filter, IOP Conference Series: Materials Science and Engineering 905, 1, 012034 (2020) https://doi.org/ 10.1088/1757-899X/905/1/012034

4. S. Ovchinnikova, D. Abornev, M. Kalinichenko, A. Kalinichenko, A. Sekisov, Optimizing the temperature stress for the furnace volume of a fire-tube boiler Advances in Intelligent Systems and Computing, Springer 1259 (2021), 601-610 (2020) https://doi.org/10.1007/978-3-030-57453-6_57

5. M. Ovchinnikova, N. Kalinichenko, E. Markina, E. Schneider, Energy modernization of housing stock, E3S Web of Conferences 157, 06028 (2020) DOI: https://doi.org/10.1051/e3sconf/202015706028

6. A.N. Sekisov, S.V. Ovchinnikova, M.S. Norenko, V.S. Matevosyan, Prospects for the solar energy development in housing construction: An assessment of economic efficiency, IOP Conference Series: Materials Science and Engineering 913(4), 042051 (2020)

7. A. Sekisov, S. Ovchinnikova, V. Grebneva, M. Chernyshova, Modern directions of low-rise housing construction development in the world: Economic and technological aspect, IOP Conference Series: Materials Science and Engineering 913(4), 042035 (2020)

8. E.N. Stratinskaya, et al. Changes in the humus state of ordinary chernozems during cyclic irrigation, Scientific journal of the Russian Research Institute of Melioration Problems 1 (1), 7 (2011)

9. E.N. Stratinskaya, T.P. Andreeva Changes in soil properties with a decrease in water load, Melioration and water management 2, 33-35 (2010)

10. E.N. Tsoraeva, Problems of rational use and protection of soils, In the collection: Results of research work for 2017, a collection of articles based on the materials of the 73rd scientific and practical conference of teachers (2018)

11. E.N. Tsoraeva, To the question of the economic efficiency of land use in the municipal formation, Omsk Scientific Vestnik. Series: Society. History. Modernity 5, 3, 141-146 (2020)

12. M.V. Kataeva, Ecological and economic problems of integrated development and development of territories, Life safety 3, 207, 51-53 (2018) 